\title{
Increased corticosteroid binding capacity of plasma albumin but not of corticosteroid-binding globulin caused by ACTH-induced changes in free fatty acid concentrations in snowshoe hares and rabbits
}

\author{
R Boonstra and A A Tinnikov ${ }^{\mathbf{1}}$ \\ Division of Life Sciences, Scarborough Campus, University of Toronto, Scarborough, Ontario, Canada M1C 1A4, and ${ }^{1}$ Institute of Cytology and Genetics, \\ Novosibirsk 90, 630090 Russia \\ (Requests for offprints should be addressed to R Boonstra)
}

\begin{abstract}
Free fatty acids (FFAs) are rapidly mobilized by ACTH and have been shown to be potent endogenous modulators of steroid-protein interactions. We increased FFA in lagomorphs by ACTH and then separated the transient increase in glucocorticoid binding capacity of plasma into that accounted for by changes in binding to albumin and to corticosteroid-binding globulin (CBG). Sequential injections of dexamethasone and ACTH into both snowshoe hares and laboratory rabbits resulted in the rapid mobilization of FFA only after the ACTH injection. The maximum corticosteroid binding capacity increase paralleled that of the FFA increase in both species. In rabbits, CBG levels remained constant over the duration of the
\end{abstract}

experiment. Corticosterone binding by rabbit albumin increased in a dose-dependent fashion in response to increases in FFA (oleic and linoleic acid) concentrations. Finally, by stimulating FFA release in snowshoe hares with $\mathrm{ACTH}$ and separating the increase in corticosteroid binding capacity through selective denaturing of CBG by heat, we determined that the increase in plasma binding capacity was a response to changes in binding by albumin, not CBG. Thus FFA released in response to stressors in lagomorphs may effect short-term increases in steroid binding.

Journal of Endocrinology (1998) 156, 205-212

\section{Introduction}

The stress response is critical in permitting mammals to respond adaptively to potentially harmful environmental challenges. Acting through the hypothalamic-pituitaryadrenocortical feedback system, a stressor causes the rapid mobilization of adrenal corticosteroids (CORT) (Munck et al. 1984). The availability of circulating corticosteroids for target tissues is mediated by serum corticosteroidbinding globulin (CBG), which acts as the carrier protein for CORT. When bound to CBG, CORT is biologically inactive (Siiteri et al. 1982) and, under basal conditions, 90-95\% of plasma CORT is bound to CBG. Though CBG levels are known to show long-term (after $24 \mathrm{~h}$ or more) declines in response to stressors (Fleshner et al. 1995), CBG levels are thought to have little capacity for rapid short-term changes. Thus, in response to a stressor, the rapid release of CORT apparently results in a major transitory pulse of free CORT as the binding capacity of CBG is swamped (Westphal 1971, Dallman et al. 1989).

Two recent reports call into question the short-term stability of the binding capacity of CBG. First, rapid increases in plasma free fatty acids (FFA) caused by heparin-induced lipolysis resulted in a 2- to 3-fold increase in corticosterone binding to CBG in rats (Haourigui et al. 1993). This increase was the result of conformational changes in the CBG molecule, causing an increase in the apparent number of binding sites, though not in the affinity constant. The increased binding lasted approximately $2 \mathrm{~h}$. Thus, presumably, any endogenous component causing the rapid mobilization of FFA should have similar effects on CBG. Second, in wild snowshoe hares (Lepus americanus) (a member of the lagomorph family) the injection of adrenocorticotropic hormone (ACTH), but not dexamethasone (DEX), resulted in a rapid increase in the maximum corticosteroid binding capacity (MCBC) of plasma to about 1.4 times that of baseline values and this effect also lasted for about $2 \mathrm{~h}$ (Boonstra \& Singleton 1993). ACTH is known to be a potent lipolytic hormone (Boston \& Cone 1996), especially in the rabbit (also a lagomorph) (Rudman \& DiGirolamo 1967, Desbals et al. 1970). Thus, we hypothesize that ACTH causes the rapid mobilization of FFA in lagomorphs which then results in the short-term increase in the binding capacity of CBG.

We examined this hypothesis with four experiments. First, since we initially observed a rapid change in MCBC 
in snowshoe hares following an injection of synthetic ACTH (Boonstra \& Singleton 1993), we tested whether these rapid changes in MCBC were correlated with similar rapid changes in FFA in a new sample of hares caught in 1992. Second, we tested whether similar changes occurred in MCBC and FFA levels in laboratory rabbits and whether CBG levels remained constant. Third, since albumin is the most abundant protein in plasma and the major carrier of FFA (Peters 1996), and since FFAs are known to enhance the binding of a variety of steroids by albumin (Ryan \& Chopra 1976, Soltys \& Hsia 1977), we assessed how corticosteroid binding by rabbit albumin is affected in vitro by changes in FFA levels. Fourth, to assess the relative importance of FFA on albumin and on CBG in affecting changes in the maximum binding capacity of plasma for cortisol in snowshoe hares, we partitioned the effect of FFA on these two blood proteins by selectively denaturing CBG (Sandberg et al. 1966, Westphal 1970).

\section{Materials and Methods}

\section{Chemicals}

Corticosterone, cortisol, rabbit albumin, oleic acid and linoleic acid were all purchased from Sigma Chemicals Co. (St Louis, MO, USA). $\left[1,2,6,7-{ }^{3} \mathrm{H}\right]$ cortisol and $[1,2,6,7-$ $\left.{ }^{3} \mathrm{H}\right]$ corticosterone were purchased from Amersham Canada (Mississauga, Ontario, Canada). DEX sodium phosphate was purchased from Sabex (Montreal, Canada) and ACTH was purchased as Synacthen Depot from CIBA (Ontario, Canada). All reagents used in the RIAs were of analytical grade and redistilled prior to use.

\section{Animals and plasma protocol}

The snowshoe hares for experiments 1 and 4 were obtained in the southern Yukon along the Alaska Highway near the Arctic Institute Base at Kluane Lake. Hare populations typically fluctuate over a 10-year cycle throughout the boreal forests of North America (Krebs et al. 1995). Hares were live-trapped and handled as described by Boonstra \& Singleton (1993). In 1992 (experiment 1), hares were obtained from 16-26 February and in 1996 (experiment 4), hares were obtained on 7 May. Briefly, live-traps were set in the forest along the highway at 2200-2400 h, hares were removed from the traps by $0600 \mathrm{~h}$, transferred to burlap bags, taken to a field laboratory, and allowed to habituate for $3 \mathrm{~h}$ before the experiment started. In the 1992 sample, because hares were in the second year of the population decline (Krebs et al. 1995) and were very rare, we were forced to use both sexes (three males and six females). Results from both sexes were combined as we found no statistical difference between them (see below). In 1996 hares were in the increase phase and abundant and we used only males.
Adult male New Zealand White rabbits ( $n=8 ; 5$ months old) were used in experiment 2. They were housed in individual cages $(40 \times 60 \times 80 \mathrm{~cm})$, maintained under a $12 \mathrm{~h}$ light, 12 darkness photoperiod (lights on 07001900 h). Colony temperature was maintained at $20^{\circ} \mathrm{C}$ and rabbits had free access to water and rabbit chow. Care and use of the animals were in accordance with the Canadian Council of Animal Care and protocols were approved by the University of Toronto Animal Care Committee.

\section{Injection protocol}

Snowshoe hares The same general protocol as in Boonstra \& Singleton (1993) was followed. In 1992, each hare was bled five times from an ear artery. Blood from the first sample (called the BASE bleed, $0.5 \mathrm{ml}$ ) was used to obtain baseline estimates of blood parameters. This was immediately followed with an injection of $0.4 \mathrm{mg} / \mathrm{kg}$ of DEX into an ear vein. The second bleed (called the DEX bleed, $0.3 \mathrm{ml}$ ) occurred $2 \mathrm{~h}$ later, followed immediately by an intramuscular injection in the thigh of 4 IU of synthetic ACTH. The remaining bleeds (all $0.3 \mathrm{ml}$ ) were conducted at 30, 60, and $240 \mathrm{~min}$ after ACTH injection (called the P30, P60, and P240 bleeds respectively). In 1996, since we knew that DEX had no effect on FFA levels, hares were only injected with ACTH following the BASE bleed and bled 30, 60, and 120 min later.

Laboratory rabbits Each rabbit was bled five times from an ear artery. Blood from the first sample (called the BASE bleed, $0.5 \mathrm{ml}$ ) was used to obtain baseline estimates of blood parameters and sampling was performed between 0730 and $0800 \mathrm{~h}$. This was immediately followed with an injection of $0.4 \mathrm{mg} / \mathrm{kg}$ of DEX into an ear vein. The second bleed (called the DEX bleed, $0 \cdot 3 \mathrm{ml}$ ) occurred $2 \mathrm{~h}$ later, followed immediately by an intramuscular injection in the thigh of $4 \mathrm{IU}$ of synthetic ACTH. The remaining bleeds (all $0.3 \mathrm{ml}$ ) were obtained at 30,60, and $120 \mathrm{~min}$ after ACTH injection (called the P30, P60, and P120 bleeds respectively). During the period of the bleeds, animals were prevented from eating and drinking.

\section{Hormone assays}

Cortisol assay Since the main glucocorticoid in hares is cortisol, we measured total plasma cortisol by RIA (Boonstra \& Singleton 1993), using antibody A-155 obtained from Western Chemical (Fort Collins, CO, USA) $(1.4 \%$ cross-reaction to corticosterone). The intra- and interassay coefficients of variation for cortisol were 10 and $16 \%$ respectively. To calculate the concentrations of free cortisol we used the calculation procedures outlined by Tait \& Burstein (1964) and for these calculations we needed the albumin concentration in plasma, the ratio of albumin-bound to free cortisol, and the affinity constant of 
CBG for cortisol. Pure albumin was obtained through a trichloroacetic acid method (Michael 1962). This albumin was then used as a standard to calculate the concentration of albumin in plasma by a chromographic method (Debro et al. 1957). We calculated that hares have $3.93 \mathrm{~g}$ albumin per $100 \mathrm{ml}$ plasma. The ratio of albumin-bound to free cortisol in a $1 \%$ solution is 0.39 . The CBG affinity constant for snowshoe hares was measured in a microdialysis system (Englund et al. 1969) modified to 12 chambers (A J Bradley, personal communication) using $60 \mu \mathrm{l}$ samples of plasma diluted 1:5 with a phospho-saline buffer $(0.05 \mathrm{M}$, $\mathrm{pH} 7 \cdot 4)$. In this system, equilibrium was established in $12 \mathrm{~h}$ at $37^{\circ} \mathrm{C}$, following which the specific activities of dialysate and sac contents were measured in a scintillation counter. The concentration of CBG-bound and unbound cortisol was calculated by the method described in Paterson \& Hills (1967) and the CBG affinity constant calculated by Scatchard analysis (Scatchard 1949). We calculated the association constant for the CBG of the snowshoe hare to be $5.05 \times 10^{7} \mathrm{l} / \mathrm{mol}$. This is comparable to the estimate obtained for the laboratory rabbit $\left(4 \cdot 0 \times 10^{7} 1 / \mathrm{mol}\right)$ (Westphal 1967).

Corticosterone assay Since rabbits produce primarily corticosterone, but also some cortisol (Slight et al. 1994), both glucocorticoids were measured, using the method as validated by Boonstra \& Singleton (1993). For corticosterone, antibody B3-163 obtained from Endocrine Sciences (Tarzana, CA, USA) was used as it was highly specific $(0.4 \%$ cross-reaction to cortisol), and for cortisol antibody A-155 (above) was used. The assay was sensitive to $10 \mathrm{pg} / 10 \mu \mathrm{l}$. Intra- and inter-assay coefficients of variation were less than 5 and $10 \%$ respectively.

CBG assay CBG levels were measured by a radioligand method (Hammond \& Lahteenmaki 1983). Briefly, endogenous steroids were removed by treating $10 \mu \mathrm{l}$ of plasma with dextran coated charcoal (DCC, $0 \cdot 2 \%$ charcoal, $0.02 \%$ dextran) at room temperature for $30 \mathrm{~min}$. After centrifuging to remove the DCC, $0.1 \mathrm{ml}$ of diluted serum (final dilution 1:100 or 1:500) was incubated with a saturating solution of $\left[{ }^{3} \mathrm{H}\right]$ cortisol $(1 \mathrm{pmol})$ without (total binding) or with (non-specific binding) addition of $200 \mathrm{pmol}$ of non-radioactive cortisol for $1 \mathrm{~h}$ at room temperature and $15 \mathrm{~min}$ in an ice-bath. DCC (at $2{ }^{\circ} \mathrm{C}$ ) was used for removing unbound hormone. The radioactivity of supernatant was counted at 50\% efficiency.

MCBC assay The MCBC of the plasma was measured by a saturation ligand method (McDonald et al. 1981). Briefly $\left[{ }^{3} \mathrm{H}\right]$ cortisol, diluted in non-radioactive cortisol to known specific activity 5 - to 20 -fold in excess of the expected capacity was added to $10 \mu \mathrm{l}$ plasma (analyzed in duplicate). We allowed for the contribution of the endogenous corticosteroids in the sample. The high-affinity fraction, diluted in $0.5 \mathrm{ml}$ phosphate buffer, was measured by liquid scintillation after separation from the free- and albumin-bound fractions with DCC at $4{ }^{\circ} \mathrm{C}$ for $10 \mathrm{~min}$. The high-affinity-bound corticosteroid was then calculated knowing the specific activity and the radioactivity in the bound fraction.

\section{FFA analysis}

Total FFAs were measured by the method of Laurell \& Tibbling (1967). To obtain adequate levels of FFA, $50 \mu \mathrm{l}$ of plasma were extracted.

\section{Effect of FFA on albumin binding of corticosterone}

Rabbit albumin was made up at a concentration of $40 \mathrm{mg} / 5 \mathrm{ml}$ in phosphate buffer, $\mathrm{pH} 7 \cdot 4$. Oleic acid and linoleic acid were each made up in chloroform at a concentration of $10 \mathrm{mM}$ and 5,10 , and $20 \mu \mathrm{l}$ were dried down in duplicate test tubes. Fifty microliters of the albumin solution and $450 \mu \mathrm{l}$ of buffer (containing $10 \mathrm{ng}$ of cold corticosterone and 10000 counts of ${ }^{3} \mathrm{H}$ [corticosterone]) were added. Tubes were vortexed, incubated at $37^{\circ} \mathrm{C}$ for $15 \mathrm{~min}$, vortexed again, and incubated overnight at $4{ }^{\circ} \mathrm{C}$. Next morning, tubes were transferred to an ice bath and $200 \mu \mathrm{l}$ of DCC added. After $10 \mathrm{~min}$, tubes were centrifuged at $2000 \mathrm{~g}$, and $500 \mu \mathrm{l}$ of supernatant counted.

\section{Effect of FFA on plasma CBG and albumin}

To determine the relative contribution of $\mathrm{CBG}$ and of albumin to an increase in MCBC in plasma when FFA was stimulated, we challenged a sample of wild snowshoe hares with an ACTH test as above. For each plasma specimen, one duplicate set of $10 \mu \mathrm{l}$ samples was analyzed as above to assess total MCBC and a second set was heated to $60{ }^{\circ} \mathrm{C}$ in a water bath for $30 \mathrm{~min}$ and then analyzed as above. The latter treatment will denature the CBG (Sandberg et al. 1966, Westphal 1970) but leave albumin unaffected (Peters 1996), thus giving us only the binding to albumin. By subtracting the albumin-bound cortisol from the total binding capacity of the plasma, we calculated that bound only to CBG.

\section{Statistical analysis}

A repeated measures ANOVA was carried on the data from the hares and rabbits challenged with the hormones. Cochran's test (Winer 1971) was used to test for homogeneity of variance. We found that the data satisfied this criterion and hence we did not transform it. All ANOVAs were performed using SuperANOVA (Gagnon et al. 1990). In a repeated measures design, the values recorded from the same animal will be correlated with each other and thus are not independent as assumed by ANOVA. To compensate for this, we used the conservative GreenhouseGeisser epsilon to adjust the degrees of freedom before 


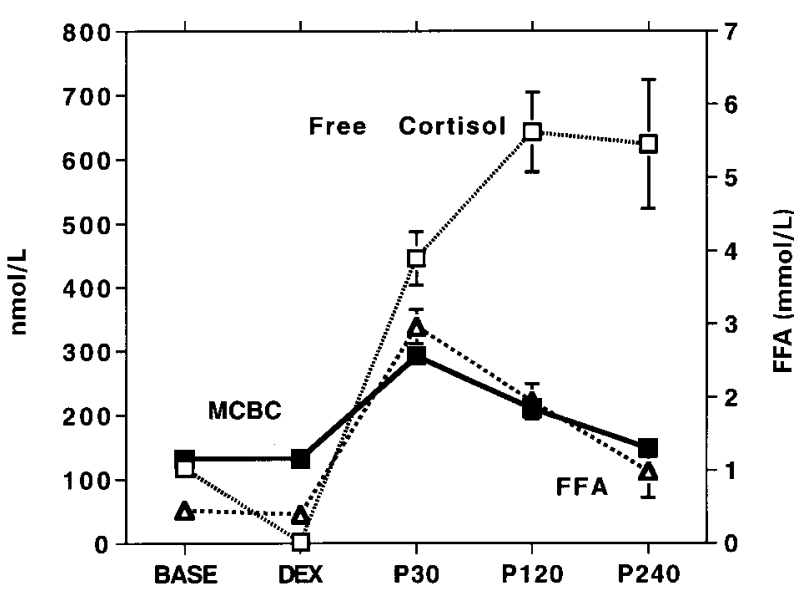

Figure 1 Response over time in plasma concentrations (means \pm S.E.M.) of free cortisol, MCBC, and FFA in snowshoe hares. BASE levels indicate initial values, DEX indicates values $2 \mathrm{~h}$ after DEX injection, and P30, P120, and P240 indicate values 30, 120 , and $240 \mathrm{~min}$ after ACTH injection.

calculating the probabilities (Keppel 1982). We used the Tukey-Kramer multiple comparison post-hoc test to examine the significance of main effects. Data are expressed as means \pm s.E.M.

\section{Results}

\section{Effect of changes in FFA levels in snowshoe hares}

We first tested to see whether there were significant differences between males and females in any of the variables we examined or whether there was an interaction effect between sex and time and found none (free cortisol, main effect $F=1 \cdot 88$, d.f. $1,28, P=0 \cdot 21$ and interaction effect $F=0 \cdot 72$, d.f. $4,28, P=0 \cdot 59 ;$ MCBC, main effect $F=0 \cdot 41$, d.f. $1,28, P=0.54$ and interaction effect $F=0.77$, d.f. 4,28, $P=0.56$; FFA, main effect $F=1 \cdot 78$, d.f. 1,28, $P=0.31$ and interaction effect $F=0 \cdot 20$, d.f. $4,28, P=0 \cdot 94$ ). Hence, both sexes were pooled and only the changes with time and treatment were examined. There were significant differences over time for each of the three variables examined (free cortisol, $F=210 \cdot 71$, d.f. 4,32, $P<0 \cdot 0001$; $\mathrm{MCBC}, F=32 \cdot 84$, d.f. $4,32, P<0 \cdot 0001$; FFA, $F=28 \cdot 42$, d.f. $4,32, P<0 \cdot 0001$ ). Figure 1 (indicates that DEX caused a marked decline in cortisol levels to values approaching zero but it had no effect on either MCBC or FFA levels. However, within $30 \mathrm{~min}$ of injecting ACTH, levels of all variables increased dramatically. Free cortisol levels rose to 3.8 times baseline levels at P30 and increased even further thereafter, reaching $5 \cdot 3$ times baseline levels by P240. In contrast, MCBC levels rose to $2 \cdot 2$ times baseline levels at P30, but declined by P240 back to baseline levels. FFA levels showed a similar response, increasing to 6.4 times baseline levels at P30 and declining by P240 to $2 \cdot 3$ times baseline levels.
To assess the strength of the relationship between changes in FFA and changes in MCBC, we calculated the $r^{2}$ for all the points combined, but rather than using the total number of data points for the calculation of the correct number of degrees of freedom (i.e. 45 because each animal contributed 5 points and thus these points were not independent), we used the number of animals in the experiment as an extremely conservative estimate for the calculation of the correct degrees of freedom. The $r^{2}$ for the relationship between FFA and MCBC was 0.62 $(t=8 \cdot 42$, d.f. $7, P<0 \cdot 0005)$. Thus variation in FFA levels explained much of the variation in MCBC levels.

\section{Effect of changes in FFA levels in laboratory rabbits}

Corticosteroid levels were low at the BASE bleed (corticosterone, $11 \cdot 7 \pm 2 \cdot 3 \mathrm{nmol} / \mathrm{l}$; cortisol, $1 \cdot 4 \pm 0 \cdot 3$ ), showed little response to DEX, and then rapidly increased after the ACTH injection (corticosterone, $F=98 \cdot 38$, d.f. 4,28, $P<0 \cdot 0001$; cortisol, $F=98 \cdot 45$, d.f. 4,28, $P<0 \cdot 0001$ ) (Fig. 2). Maximum corticosterone levels occurred at P120 $(315 \cdot 0 \pm 28 \cdot 8 \mathrm{mmol} / \mathrm{l})$ and were about 27 times those of BASE values. Maximum cortisol levels occurred at P60 $(28.2 \pm 1.5 \mathrm{mmol} / \mathrm{l})$ and were about 20 times those of BASE values.

FFA levels showed no response to the DEX injection, but then rapidly increased following the ACTH injection to reach maximum values at $\mathrm{P} 60$ (17 times BASE levels) $(F=153.68$, d.f. 4,28, $P<0.0001) \quad$ (Fig. 2). Similarly, $\mathrm{MCBC}$ levels showed no response to the DEX injection, but rapidly increased following the ACTH injection to reach maximum values at P60 (1.4 times BASE levels) $(F=40 \cdot 93$, d.f. $4,28, P<0 \cdot 0001)$. In contrast, CBG levels were unaffected by either DEX or ACTH injections, showing no significant change with time $(F=0 \cdot 96$, d.f. 4,28, $P=0 \cdot 42)$. CBG levels at the BASE bleed $(259 \cdot 5 \pm$ $22.9 \mathrm{nmol} / \mathrm{l})$ were about $44 \%$ of those calculated for MCBC levels at the BASE bleed $(586 \cdot 1 \pm 69 \cdot 0 \mathrm{nmol} / \mathrm{l})$. To examine the relationship between the changes in FFA levels and the changes in MCBC levels, we calculated the $r^{2}$ for all the points combined, and, as above, used the number of animals to estimate the degrees of freedom. The $r^{2}$ for the relationship between FFA and MCBC was $0 \cdot 36$ $(t=4 \cdot 63$, d.f. $6, P<0 \cdot 004)$ and that between FFA and CBG was $0 \cdot 003(t=0 \cdot 35$, d.f. $7, P=0 \cdot 74)$. Thus variation in FFA levels explained some of the variation in MCBC levels, but none of that in CBG levels.

\section{Effect of FFA levels on steroid binding of albumin}

Increasing FFA concentrations led to a direct increase in albumin binding of corticosterone (Fig. 3). We found significant effects of the kind of FFA (2-way ANOVA: $F=6 \cdot 77$, d.f. $1,6, P=0 \cdot 04$, linoleic $>$ oleic) and of FFA concentration $(F=63 \cdot 24$, d.f. 2,6, $P<0 \cdot 0001$, $5 \mathrm{mM}<10 \mathrm{mM}<20 \mathrm{mM}$ ), but no interaction effect 

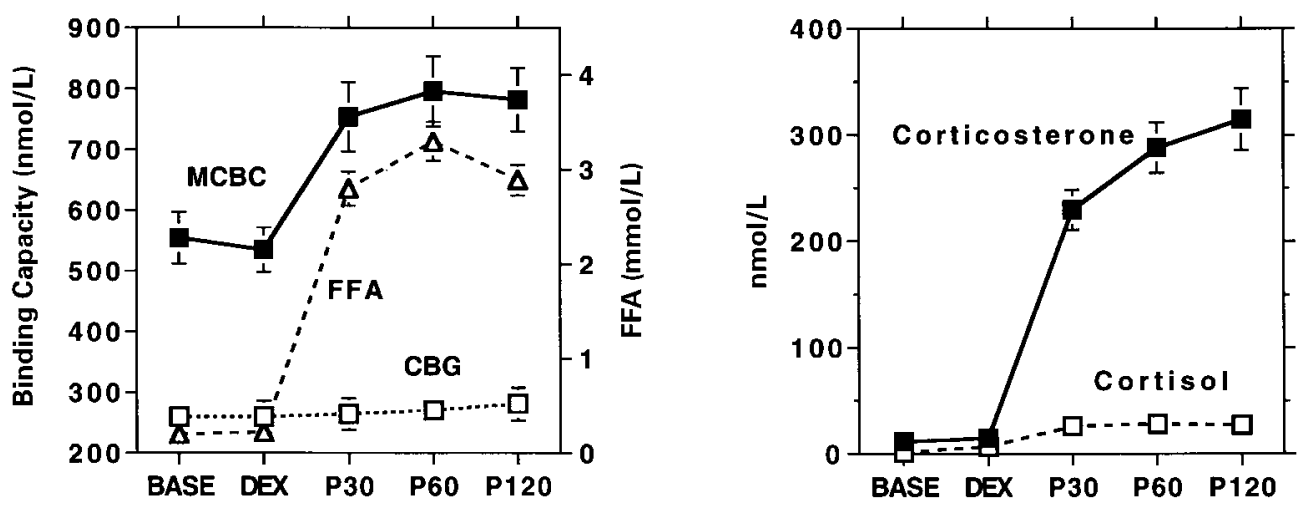

Figure 2 Response over time in plasma concentrations (means \pm S.E.M.) of (a) MCBC, CBG, and FFA and (b) free corticosterone and free cortisol in domestic rabbits. BASE levels indicate initial values, DEX indicates values $2 \mathrm{~h}$ after DEX injection, and P30, P60, and P120 indicate values 30, 60, and 120 min after ACTH injection.

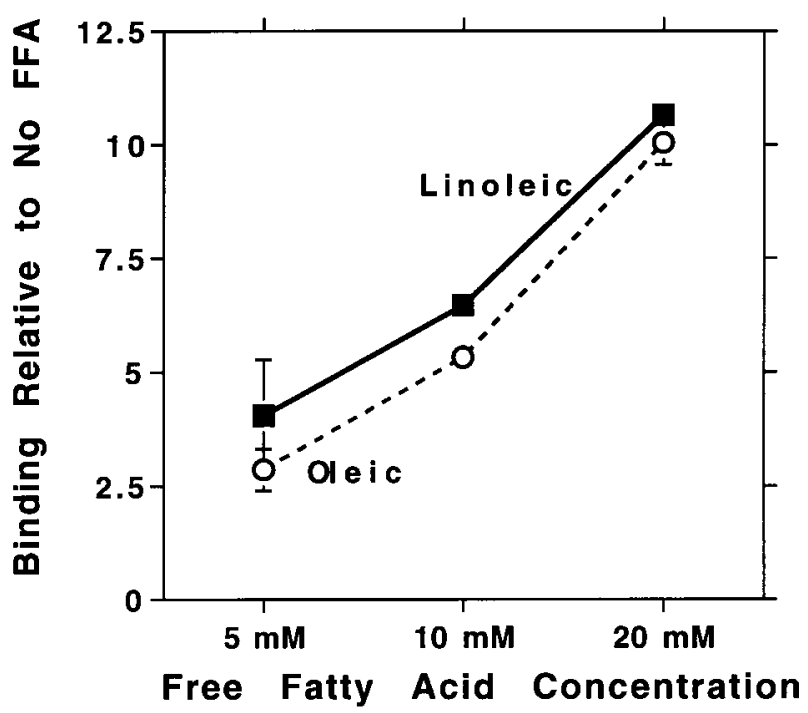

Figure 3 Changes in binding of corticosterone (means \pm S.E.M.) by rabbit albumin in response to changes in FFA concentrations. Values are presented as the binding relative to zero FFA.

$(F=0 \cdot 20$, d.f. $2,6, P=0 \cdot 98)$. Increasing the degree of unsaturation from oleic (one double bond) to linoleic (two double bonds) increased binding of corticosterone by albumin at each concentration by about $21 \%$. The slopes of the lines of the two FFAs were not significantly different (ANCOVA: $F=0 \cdot 04$, d.f. $1,8, P=0 \cdot 84$ ).

\section{Effect of FFA on albumin and CBG in snowshoe hares}

When snowshoe hares were injected with ACTH, the levels of free cortisol increased significantly $(F=4 \cdot 42$, d.f. $3,9, P<0 \cdot 05)$ as in the first experiment. For the purposes of this experiment, we focus on the changes in MCBC. By partitioning the total corticosteroid binding capacity into that accounted for by binding to albumin (heat treated plasma) and to CBG (total MCBC minus albumin-bound)

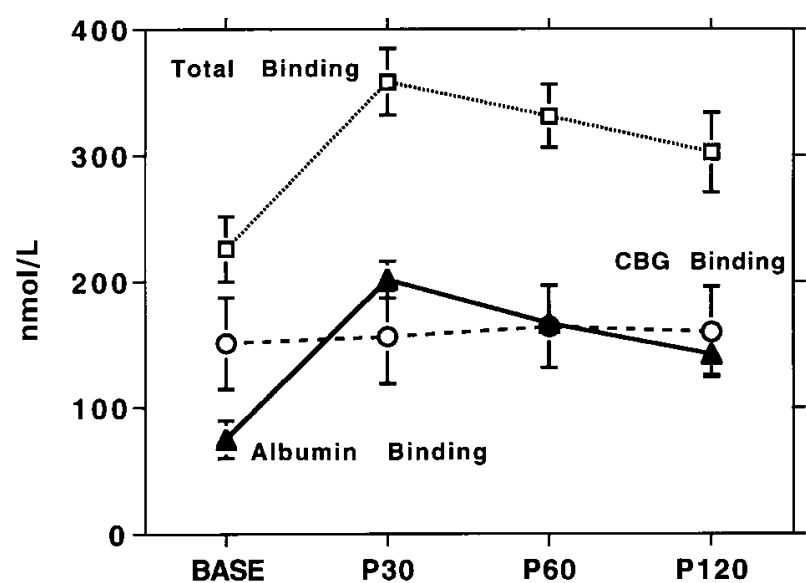

Figure 4 Response over time in binding of cortisol by male snowshoe hare plasma (means \pm S.E.M.) in response to an ACTH injection. BASE levels indicate initial values and P30, P60, and P120 indicate values 30,60 , and $120 \mathrm{~min}$ after the ACTH injection. Total MCBC for cortisol was separated into that bound by albumin and that bound by CBG by heat denaturing CBG $\left(60{ }^{\circ} \mathrm{C}\right.$ for $\left.30 \mathrm{~min}\right)$.

we were able to determine which plasma component was responding to the changes in FFA caused by the ACTH injection (demonstrated in experiments 1 and 2 above). There were significant changes in total binding capacity following the ACTH injection $(F=41.97$, d.f. 3,9, $P<0 \cdot 0001)$ and in albumin binding capacity $(F=103 \cdot 92$, d.f. $3,9, P<0 \cdot 0001)$, but not in CBG binding capacity $(F=0.44$, d.f. 3,9, $P=0.73)$. Thus, changes in total binding capacity were a result of changes in albumin binding capacity, not of changes in CBG binding capacity (Fig. 4).

\section{Discussion}

Our study has demonstrated that in hares and in rabbits increases in FFA, released as a consequence of ACTH but 
not DEX, increase the binding capacity of plasma for glucocorticoids and that this is the result of increased binding by plasma albumin. This evidence is thus consistent with that on testosterone and progesterone in which FFA interactions with plasma albumin affect the binding capacities for these hormones (Westphal 1986). Serum albumin is the principal agent for transporting FFA in the blood (Peters 1996), has about six binding sites for FFA, and binds FFA strongly (association constants for FFA such as stearic, palmitic, and oleic are in the order of $10^{7} 1 / \mathrm{mol}$ ). We found no contribution of $\mathrm{CBG}$ to the increased corticosteroid binding with increasing FFA levels (Figs 2 and 4).

Two caveats should be addressed prior to discussing the data. First, since hares and rabbits differ in their major adrenal glucocorticoid (cortisol versus corticosterone respectively), our findings may not be directly comparable. We needed a laboratory model that could be used under controlled conditions to understand the MCBC changes first reported in snowshoe hares by Boonstra and Singleton (1993). Ideally we would have liked to have used a laboratory analog of the same genus as hares (Lepus), but to our knowledge, none is available, and thus we elected to go for the domestic laboratory rabbit (Oryctolagus) as the closest related equivalent. In addition, in rabbits adipose tissue is known to be highly sensitive to ACTH (Rudman \& DiGirolamo 1967, Desbals et al. 1970), but, prior to our work, it was unknown whether a wild relative, hares, would respond in the same fashion, given that it has a different primary adrenal glucocorticoid. However, both species respond in a similar manner to an injection of DEX (no FFA mobilization, no change in MCBC) and of ACTH (rapid FFA mobilization, rapid MCBC increase), which is to be expected given a common evolutionary origin. Why hares use cortisol as their primary adrenal glucocorticoid and rabbits use corticosterone is unknown and may possibly be related to the fact that cortisol is a more potent glucocorticoid and hares tend to have a cursorial life style, especially in escape from predators, and rabbits a more sedentary one, relying on warrens to escape from predators.

Second, the stress that animals experienced independent of our experimental injections may have compromised the interpretation of our results. Snowshoe hares were clearly stressed prior to the start of our treatment. To assess the impact of trapping and handling on the stress response of hares, Boonstra and Singleton (1993) got resting levels of cortisol and MCBC by collecting a sample of hares in 1991 by shooting them. Cortisol levels in the shot hares were about 4 times lower than those in experimentally handled hares at the BASE bleed but MCBC levels were similar. Thus the stress of handling was either insufficient to elicit an MCBC response (via an FFA increase) or more likely, the response occurred, and FFA levels had returned to approximate resting levels by the time the first bleed occurred (as they did $4 \mathrm{~h}$ (P240) after the ACTH injec- tion, Fig. 1). Thus we do not think the stress of handling compromised our results, as hares responded to both DEX and $\mathrm{ACTH}$ as expected and retained a tremendous capacity to mobilize both cortisol and FFA and to increase MCBC levels given an artificial ACTH challenge. Rabbits in our experiments may also have been stressed because we did not allow them to feed during the $4 \mathrm{~h}$ of the experiment. This indeed may have been a complicating factor and we did not control for it, though we think its significance is minor relative to the size of the effect we observed (no increase in FFA for the first $2 \mathrm{~h}$ after the DEX injection; a 13-fold increase in FFA 30 min after the ACTH injection). In contrast, in an experiment by Edson et al. (1975), fasting female rabbits for $48 \mathrm{~h}$ resulted in only a 2-fold increase in FFA levels. Thus we think the length of the fasting our rabbits experienced was too short to have had a significant impact on our results.

In rats the corticosteroid binding capacity of plasma was found to increase following an increase in FFA levels (Haourigui et al. 1993) (induced by lipolysis as a result of a heparin injection), but this was attributed entirely to conformational changes in the CBG molecule induced by FFA (unsaturated acids only). The evidence they (Haourigui et al. 1993) presented is, in general, convincing, but they did not exclude the potential role of albumin. In addition, it is possible that mechanisms other than those they propose may explain part of their results. Specifically, from their in vivo studies on control and heparin treated rats (FFA enhanced plasma), they were not able to detect a difference either in the electrophoretic mobility of CBG or in the immunoreactivity of the CBG, whereas from their in vitro studies marked effects of FFA were found. However, in vitro, they used highly purified samples of CBG, whereas in vivo, albumin would be present in much higher concentrations than CBG (approximately 0.5-0.6 mM). It is possible that in vivo almost all plasma FFA is bound to albumin and thus unavailable for interaction with CBG, whereas in a purified situation (i.e. in vitro) when albumin was not present, all the FFA interacts with CBG. This may account for the inconsistency in results between in vivo (plasma) and in vitro (pure $\mathrm{CBG}$ ) responses to FFA (Haourigui et al. 1993).

Thus, our data clearly indicate that the in vivo response of plasma to FFA in lagomorphs in terms of corticosteroid binding was entirely due to albumin (Fig. 4). However, the physiological significance of the changes in corticosteroid binding capacity of plasma may be independent of whether albumin or CBG is the main site for the action of FFA. What may be critical is how much of the total circulating hormone is free (bioactive) versus how much is bound (unavailable for target tissues) (Sitteri et al. 1982), with the bound fraction being both CBG-bound and albumin-bound. Thus any method to measure the glucocorticoid binding capacity of CBG which either reduces the FFA present in the plasma sample (pretreatment of plasma at room temperature with DCC will strip over $50 \%$ 
of the FFA from the plasma (R Boonstra \& A A Tinnikov, unpublished observations, see also Chen 1967)) or which may ignore the influences of FFA entirely by measuring the absolute amount of CBG present (such as antibody assessment of CBG levels), is likely to miss the rapid, short-term plasma changes in MCBC induced by an FFA surge.

The effect of ACTH stimulation on FFA mobilization may represent a mechanism of metabolic homeostasis. FFAs are a major fuel during prolonged physical activity, especially in the absence of food intake (Felber \& Golay 1995). Though glucocorticoids are known to mobilize FFA in some mammals (Rudman \& DiGirolamo 1967), DEX had no effect on FFA levels in either hares (Fig. 1) or rabbits (Fig. 2). Thus, in lagomorphs the absence of glucocorticoid lipolytic activity may be counterbalanced by the great sensitivity of adipose tissue to ACTH. Since ACTH is under negative feedback control by glucocorticoids, reducing the amount of free glucocorticoids through increased plasma binding (an effect of FFA) would aid in maintaining ACTH secretion and in maintaining lipolysis for a longer period. It remains to be established whether increased corticosteroid binding by FFA-enriched albumin affects the bioavailability to target tissues and thus the efficacy of steroid action.

\section{Acknowledgements}

We thank D Hik and C McColl for helping with the field aspects of the hare physiology study (especially during the rigors of the Yukon winter), $\mathrm{L} \mathrm{Lu}$ for assisting with the RIA assays, M Filosa for assisting with the determination of binding constants, G L Hammond for comments on the initial manuscript, and a reviewer for comments on the final one. We thank the Natural Sciences and Engineering Research Council of Canada for funding and the Centre for Advance Study, Norway for computing and administrative support. This is contribution 111 of the Kluane Boreal Forest Ecosystem Project.

\section{References}

Boonstra R \& Singleton GR 1993 Population declines in the snowshoe hare and the role of stress. General and Comparative Endocrinology 91 126-143.

Boston BA \& Cone RD 1996 Characterization of melanocortin receptor subtype expression in murine adipose tissues and in the 3T3-L1 cell line. Endocrinology 137 2043-2050.

Chen RF 1967 Removal of fatty acids from serum albumin by charcoal treatment. Journal of Biological Chemistry 242 173-181.

Dallman MF, Darlington DN, Suemaru S, Cascio CS \& Levin N 1989 Corticosteroids in homeostasis. Acta Physiologica Scandinavica 136 (Suppl 583) 27-34

Debro JR, Traver H \& Korner A 1957 The determination of serum albumin and globulin by a new method. Journal of Laboratory and Clinical Medicine $\mathbf{5 0}$ 728-732.
Desbals B, Desbals P \& Agid R 1970 Pituitary-adrenal control of fat mobilization in rabbits. In Adipose Tissue. Regulation and Metabolic Functions pp 25-48. Eds B Jeanrenaud \& D Hepp. Stuttgart: Georg Thieme Verlag.

Edson JL, Hudson DG \& Hull D 1975 Evidence of increased fatty acid transfer across the placenta during a maternal fast in rabbits. Biology of the Neonate 27 50-55.

Englund PT, Huberman JA, Jovin TM \& Kornberg A 1969 Enzymatic synthesis of deoxyribonucleic acid. XXX. Binding of triphosphates to deoxyribonucleic polymerase. Journal of Biological Chemistry 244 3038-3044.

Felber JB \& Golay A 1995 Regulation of nutrient metabolism and energy expenditure. Metabolism: Clinical and Experimental 44 (Suppl 2) 4-9.

Fleshner M, Deak T, Spenncer RL, Laudenslager ML, Watkins LR \& Maier SF 1995 A long term increase in basal levels of corticosterone and a decrease in corticosteroid-binding globulin after acute stressor exposure. Endocrinology 136 5336-5342.

Hammond GL \& Lahteenmaki PLA 1983 A versatile method for the determination of serum cortisol binding globulin and sex hormone globulin binding capacities. Clinica Chimica Acta 132 101-110.

Haourigui M, Martin ME, Thobie N, Benassayag C \& Nunez EA 1993 Stimulation of the binding properties of adult rat corticosteroid-binding globulin by a lipolysis-induced rise in plasma free fatty acids. Endocrinology 133 183-191.

Gagnon J, Roth JM, Carroll M, Hofmann R, Haycock KA, Phamondon J, Feldman DS Jr \& Simpson J 1990 SuperANOVA-Accessible General Linear Modelling. Berkeley, California: Abacus Concepts Inc.

Keppel G 1982 Design and Analysis. A Researcher's Handbook, edn 2. Englewood Cliffs: Prentice-Hall.

Krebs CJ, Boutin S, Boonstra R, Sinclair ARE, Smith JNM, Dale MRT, Martin K \& Turkington R 1995 Impact of food and predation on the snowshoe hare cycle. Science 269 1112-1115.

Laurell S \& Tibbling G 1967 Colorimetric micro-determination of free fatty acids in plasma. Clinica Chimica Acta 16 57-62.

McDonald IR, Lee AK, Bradley AJ \& Than KA 1981 Endocrine changes in dasyurid marsupials with differing mortality patterns. General and Comparative Endocrinology 44 292-301.

Michael SE 1962 The isolation of albumin from blood serum or plasma by means of organic solvents. Biochemical Journal 82 212-218.

Munck A, Guyre PM \& Holbrook NJ 1984 Physiological functions of glucocorticoids during stress and their relation to pharmacological actions. Endocrine Reviews 5 25-44.

Paterson JYF \& Hills F 1967 The binding of cortisol by ovine plasma proteins. Journal of Endocrinology 37 261-268.

Peters T Jr 1996 All About Albumin. San Diego: Academic Press.

Rudman D \& DiGirolamo M 1967 Comparative studies on the physiology of adipose tissue. Advances in Lipid Research 5 35-117.

Ryan MT \& Chopra RK 1976 The paradoxical effect of fatty acid on steroid-albumin interaction. Biochimica et Biophysica Acta 427 337-349.

Sandberg AA, Rosenthal H, Schneider SL \& Slaunwhite WR Jr 1966 Protein-steroid interactions and their role in the transport and metabolism of steroids. In Steroid Dynamics, pp 1-61. Eds G Pincus \& JR Tait. New York: Academic Press.

Scatchard G 1949 The attractions of proteins for small molecules and ions. Annals of the New York Academy of Sciences 51 827-841.

Siiteri PK, Murai JT, Hammond GL, Nisker JA, Raymoure WJ \& Kuhn RW 1982 The serum transport of steroid hormones. Recent Progress in Hormone Research 38 457-510.

Slight S, Ganjam VK, \& Weber KT 1994 Species diversity of 11 beta-hydroxysteroid dehydrogenase in the cardiovascular system. Journal of Laboratory and Clinical Medicine 124 821-826. 
Soltys BJ \& Hsia JC 1977 Fatty acid enhancement of human serum albumin binding properties. Journal of Biological Chemistry 252 4043-4048.

Tait JRS \& Burstein S 1964 In vivo studies of steroid dynamics in man. In The Hormones, Volume 5, pp 441-557. Eds G Pincus, KV Thinman \& EB Astwood. New York: Academic Press.

Westphal U 1967 Steroid-protein interactions. XIII. Concentration and binding affinities of corticosteroid-binding globulin in sera of man, monkey, rat, rabbit, and guinea pig. Archives of Biochemistry and Biophysics 118 556-567.

Westphal U 1970 Preparation and characteristics of corticosteroidbinding globulin (CBG, transcortin). In Methods in Reproductive
Endocrinology: Steroid Assay by Protein Binding, pp 122-143. Ed. E Diczfalusy. Stockholm: Karolinska Symposia on Research.

Westphal U 1971 Steroid-Protein Interactions. New York: Springer-Verlag.

Westphal U 1986 Steroid-Protein Interactions II. New York: Springer-Verlag.

Winer BJ 1971 Statistical Principles in Experimental Design, edn 2. New York: McGraw-Hill Press.

Received 27 May 1997

Accepted 26 August 1997 